ORIGINAL ARTICLE

\title{
Predictors of Adverse Outcomes of Patients with Chest Pain and Primary Diagnosis of Non-Cardiac Pain at the Time of Discharge from Emergency Department: A 30-Days Prospective Study
}

\author{
Mohammadhossien Soltani ${ }^{1}$, Masoud Mirzaei ${ }^{1}$, Ahmad Amin ${ }^{2}$, Mahmoud \\ Emami $^{1}$, Reza Aryanpoor ${ }^{3}$, Farimah Shamsi ${ }^{4}$, Mohammadtaghi \\ Sarebanhassanabadi ${ }^{1}$
}

ABSTRACT

BACKGROUND: Chest pain is a common symptom for referring patients to emergency departments (ED). Among those referred, some are admitted to hospitals with a definite or tentative diagnosis of acute coronary syndrome and some are discharged with primary diagnosis of non-cardiac chest pain. This study aimed at investigating 30 days' adverse outcomes of patients discharged from ED of a major heart center in Iran.

METHODS: Out of 1638 chest pain admissions to the centre during 2010-2011, 962 patients (mean age= $50.9 \pm 15.9$ years) who were admitted to Afshar Heart Center's ED with chest pain as their chief complaint, and discharged with primary diagnosis of non-cardiac chest pain, were followed for any adverse cardiac events 30 days post discharge. The adverse events were: unstable angina, non-STelevated myocardial infarction (NSTEMI), ST elevated myocardial infarction (STEMI), coronary revascularization (percutaneous angioplasty, coronary artery bypass grafting) and death.

RESULTS: Adverse cardiac events, including acute coronary syndrome (ACS), revascularization and death were observed in 30 patients $(3.1 \%)$ including: acute $M I n=5(0.5 \%$, sudden cardiac death inn=1 $(0.1 \%$, coronary revascularization in $n=8(0.8 \%)$ and hospitalization due to unstable angina/NSTEMI in $n=16$ (1-7\%). Adverse events were seen more frequently in patients with history of hypertension, dyslipidemia and previous coronary artery disease. In univariate analysis, the chance of postdischarge adverse cardiac events was higher in patients with hypertension $(O R=9.36, C I=3.24-27.03)$, previous coronary artery disease $(\mathrm{OR}=3.8, \mathrm{CI}=1.78-8.0)$, dyslipidemia $(\mathrm{OR}=3.5, \mathrm{CI}=1.7-7.38)$ and discharge against medical advice $(O R=2.85, C I=1.37-5.91)$.

CONCLUSION: The extent of adverse cardiac events in patients with a primary diagnosis of non-cardiac chest pain within 30 days of discharge was significant, mandating nation-wide registries to provide better care for these patients.

KEYWORDS: Chest pain, non-cardiac, cardiac, emergency, discharge, outcome

DOI: http://dx.doi.org/10.4314/ejhs.v26i4.2

\section{INTRODUCTION}

One of the most common reasons for referring patients to emergency departments (ED) is acute chest pain. This presentation suggests acute coronary syndromes (ACS). However, after diagnostic evaluation, only $15 \%-25 \%$ of these patients have ACS (1).

\footnotetext{
${ }^{1}$ Yazd Cardiovascular Research Centre, Shahid Sadoughi University of Medical Sciences, Yazd, Iran

${ }^{2}$ Rajaie Cardiovascular, Medical and Research Center, Tehran. Iran

${ }^{3}$ Golestan University of Medical Sciences, Gorgan, Iran

${ }^{4}$ Department of Epidemiology and Biostatistics, Shahid Sadoughi University of Medical Sciences, Yazd, Iran

Corresponding Author: Masoud Mirzaei, Email: mmirzaei@ssu.ac.ir
} 
Patients with presentation of chest pain are evaluated in ED considering their past medical history, physical examination, blood biomarkers, imaging modalities and exercise test. They will be either admitted to cardiac care unit (CCU), if there is probability of cardiac chest pain, or discharged from ED with a diagnosis of noncardiac chest pain.

The extent of assessmemt of patients in ED depends on hospital facilities and national guidelines, but even with these assesments some patients with cardiac chest pain may be misdiagnosed as non-cardiac chest pain and discharged from ED. Misdiagnosis of cardiac chest pain as non-cardiac may lead to serious adverse outcomes. The rate of misdiagnosis varies in different EDs, possibly due to the extent and quality of work-up done for chest pain evaluation. Several studies reported adverse outcomes of patients admitted with primary diagnosis of chest pain in ED and discharged with a diagnosis of non-cardiac chest pain in developed countries.

Loten et al., in a large study in Australia, showed that $1 \%$ of patients discharged from ED without a diagnosis of ACS, had a cardiac event within one month (1). Miller et al. showed that $2.8 \%$ of patients discharged from ED with a diagnosis of non-cardiac chest pain had an adverse cardiac event after discharge (2). Also, Montassier, in France, reported that $3.7 \%$ of patients who were discharged from ED with a diagnosis of non-cardiac chest pain had a cardiac adverse event two months of post-discharge (3). These differences, observed in different populations, depend on the extent of evaluation in ED, length of the study and the accuracy of recording the outcome during the follow-up. However, there is not much information available from developing countries. This study aimed at assessing the predictors and adverse outcomes of patients admitted to ED with primary chest pain as their chief complaint and discharged with diagnosis of non-cardiac chest pain 30-days post-discharge in a large center in Iran.

\section{METHODS}

Over six months from October 2010, we studied 1638 consecutive patients older than 25 years with primary chest pain as their chief complaint. They were evaluated by screening physicians who were mostly registrars of cardiology. The physicians took the medical history of patients, did physical examination, took serial ECGs and checked cardiac enzymes $\left(\mathrm{CK}_{\mathrm{MB}}\right.$ and cardiac troponin I) on the arrival of patients and six hours later. The setting was Afshar Heart Center (AHC), a major referral and teaching hospital located in Yazd, Iran. AHC is the only one of its kind in Yazd province and serves over $80 \%$ of the population. The service provided at AHC can be representative of the service provided to patients in Yazd province with almost one million population.

According to the latest guidelines on approach to chest pain,(4) and current practice in AHC's ED, patients were categorized in low likelihood of ischemic chest pain group if they have: 1) A non-angina chest pain according to the judgment of screening physicians, 2) A normal standard 12-lead ECG with no change in serial readings and/or no new ECG change in comparison with previous ECG and, 3) normal cardiac enzyme levels on arrival and six ours later. If all criteria were met, they were recognized as low likelihood of ischemic chest pain and discharged as non-cardiac chest pain. The patients with possible and/or definite cardiac chest-pain have been hospitalized for better evaluation and treatment.

We followed-up all patients with a primary diagnosis of non-cardiac chest pain $(n=962)$ for 30-days of post discharge. The main adverse cardiac events including hospitalization due to ACS (unstable angina/NSTEMI/STEMI), coronary revascularization, percutaneous coronary intervention (PCI), coronary artery bypass grafting (CABG) and death were investigated. Hospital charts were carefully reviewed and all relevant information was extracted. Sudden cardiac death (SCD) was defined if death occurred within one hour after the onset of chest pain.

In this study, hypertension, diabetes mellitus and dyslipidemia were considered if the patient was told by a physician that s/he had these conditions and/or if they used drugs for the conditions. There were no laboratory data for serum lipids or blood glucose during staying of 
patients in ED because the patients were not fasting.

Family history of CAD was assumed if there was history of MI or SCD in any first degree relative including men younger than 55 years old and women younger than 65 years old. Previous CAD was recorded if the patient had any history of previous coronary revascularization, definite history of previous acute coronary syndrome and/or history of stable angina or CAD in coronary angiography. Tobacco smoking was categorised as current smoker, past smoker or not smoker according to patients' self-report.

Abnormal ECG was assumed if the patient had previous abnormal ECG changes like pathologic $\mathrm{Q}$ wave, ST elevation $\geq 1 \mathrm{~mm}$ in limb leads, ST elevation $\geq 2 \mathrm{~mm}$ in precordial leads, ST depression $\geq 1 \mathrm{~mm}$, left bundle branch block (LBBB) and abnormal $\mathrm{T}$ wave. Only new changes in ECG were considered important.

Patients discharged against medical advice before three hours were recorded as discharged 'against medical advice' (DAMA) and were analyzed separately.

Continuous variables were presented as mean \pm standard deviation and categorical data presented as percentages. Student's t-test and Mann-Whitney U-test were used to compare continuous data, and Chi-square test was used for categorical data. P-value less than 0.05 was considered significant. The data were analyzed using SPSS version 15.0 (SPSS Inc.; Illinois, USA).

Ethical approval was obtained from Shahid Sadoughi University Human Research Ethics' Committee. Participation was voluntary and written informed consent was obtained from each respondent.

\section{RESULTS}

During the study, of 1638 patients referred to the ED of AHC with chief complaint of chest pain, 676 patients $(41 \%)$ were admitted to CCU as ACS, and 962 patients (59\%) were discharged from the ED. In total, 679 patients $(70 \%)$ were discharged after 6 to 12 hours with diagnosis of non-cardiac chest pain and 283 patients (30\%) were discharged as DAMA.

During a 30-day follow up, adverse cardiac events were found in 30 patients $(3.1 \%)$ who were discharged from ED (Table 1). AMI was observed in $5(0.5 \%)$, SCD in $1(0.1 \%)$, coronary revascularization in $8(0.8 \%)$, and hospitalization due to unstable angina/NSTEMI in $16(1.7 \%)$. Four patients died, three of them $(0.3 \%)$ from cardiovascular causes.

Table 1: Demographic and other baseline characteristics of patients admitted with chest pain to the emergency department of Afshar Heart Centre with and without adverse cardiac outcomes30 days after discharge.

\begin{tabular}{llll}
\hline Characteristics & $\begin{array}{l}\text { With cardiac event } \\
\mathrm{N}=30(3.1 \%)\end{array}$ & $\begin{array}{l}\text { Without cardiac event } \\
\mathrm{N}=932(96.9 \%)\end{array}$ & P-Value \\
\hline Age (mean \pm SD) & $62.3 \pm 12.1$ & $50.4 \pm 15.0$ & $<0.001^{* *}$ \\
Systolic Blood pressure(mean $\pm \mathrm{SD})$ & $147 \pm 24$ & $140 \pm 27$ & $<0.001^{* *}$ \\
Diastolic Blood pressure(mean $\pm \mathrm{SD})$ & $87 \pm 13$ & $85 \pm 13$ & $<0.001^{* *}$ \\
Heart rate(mean $\pm \mathrm{SD})$ & $76 \pm 11$ & $79 \pm 16$ & $0.238^{* *}$ \\
Male (n, \%) & $19(63.3)$ & $438(47.7)$ & $0.057^{*}$ \\
Hypertension (n, \%) & $26(86.7)$ & $382(41.0)$ & $<0.001^{*}$ \\
Diabetes mellitus (n, \%) & $12(40.0)$ & $202(21.7)$ & $0.020^{*}$ \\
Dyslipidemia (n, \%) & $15(50.0)$ & $205(22.0)$ & $0.001^{*}$ \\
Tobacco smoking (n, \%) & $4(13.3)$ & $71(7.6)$ & $0.250^{*}$ \\
Previous CAD (n, \%) & $12(40.0)$ & $140(15.0)$ & $0.001^{*}$ \\
Abnormal ECG *** & $11(36.7)$ & $203(21.8)$ & $0.001^{*}$ \\
Discharged against medical advise & $16(53.3)$ & $267(28.6)$ & $0.005^{*}$ \\
\hline
\end{tabular}

*Chi-square Test, ** T-test, *** First ECG was abnormal, and had no change in comparison with previous ECG 
Table 2 shows that the chance of post discharge adverse cardiac events was higher in patients with hypertension $(\mathrm{OR}=9.36,95 \% \quad \mathrm{CI}=3.24-27.03)$, previous $\mathrm{CAD}(\mathrm{OR}=3.8,95 \% \mathrm{CI}=1.78-8.0)$, dyslipidemia $(\mathrm{OR}=3.5,95 \% \mathrm{CI}=1.7-7.38)$, DAMA $(\mathrm{OR}=2.85,95 \% \quad \mathrm{CI}=1.37-5.91)$ and diabetes mellitus $\quad(\mathrm{OR}=2.4, \quad 95 \% \quad \mathrm{CI}=1.14-5.1)$. After adjustment for sex, previous $\mathrm{CAD}$ and pain duration, hypertension was the strongest predictor of cardiac adverse event $(\mathrm{OR}=15.39, \mathrm{CI}=3.37$ 70.13) followed by dyslipidemia $(\mathrm{OR}=4.9, \mathrm{CI}=$ 1.87-13), DAMA (OR=4, CI=1.54-10.6) and DM $(\mathrm{OR}=2.5, \mathrm{CI}=0.96-6.5)$ (Table 3).

Table 2: Predictors of 30 days' adverse cardiac outcomes in patients discharged from the emergency department of Afshar Heart Centre in 2011

\begin{tabular}{lllll}
\hline $\begin{array}{l}\text { Variable } \\
\mathrm{N}(\%)\end{array}$ & $\begin{array}{l}\text { With cardiac event } \\
\mathrm{N}=30\end{array}$ & $\begin{array}{l}\text { Without cardiac event } \\
\mathrm{N}=932\end{array}$ & Odds Ratio(CI) & P-value* \\
\hline Male & $19(63.3)$ & $438(47.7)$ & & 0.057 \\
\hline $\begin{array}{l}\text { Hypertension } \\
\begin{array}{l}\text { Diabetes } \\
\text { mellitus }\end{array}\end{array}$ & $26(86.7)$ & $382(41.0)$ & $9.36(3.24,27.03)$ & $<0.001$ \\
$\begin{array}{l}\text { Dyslipidemia } \\
\text { Tobacco }\end{array}$ & $12(40.0)$ & $202(21.7)$ & $2.4(1.14,5.1)$ & 0.021 \\
smoking & $4(13.3)$ & $205(22.0)$ & $3.55(1.7,7.38)$ & 0.001 \\
$\begin{array}{l}\text { Family history } \\
\text { Previous CAD }\end{array}$ & $1(3.3)$ & $71(7.6)$ & $1.9(1.27,5.5)$ & $<0.001$ \\
$\begin{array}{l}\text { Discharged } \\
\text { against medical } \\
\text { advise }\end{array}$ & $16(40.0)$ & $32(3.4)$ & $0.98(0.13,7.34)$ & 0.970 \\
\hline
\end{tabular}

Table 3: Determinants of cardiac outcome in patients discharged from the emergency department of Afshar Heart Centre in 2011.

\begin{tabular}{lll}
\hline & With cardiac event /Without cardiac event \\
\cline { 2 - 3 } & Unadjusted & Adjusted for Gender, Previous \\
& (base model) & CAD and Pain duration \\
\hline Hypertension & OR=9.35 & OR=15.39 \\
& CI: $(3.24,27.08)$ & CI: $(3.37,70.13)$ \\
\hline Diabetes mellitus & OR=2.4 & OR=2.5 \\
& CI: $(1.14,5.08)$ & CI: $(.96,6.5)$ \\
\hline Dyslipidemia & OR=3.5 & OR=4.9 \\
& CI: $(1.7,7.36)$ & CI: $(1.87,13)$ \\
\hline Discharged against & medical & OR=2.85 \\
advise & CI: $(1.37,5.9)$ & OR=4 \\
\hline
\end{tabular}

Binary logistic regression

\section{DISCUSSION}

This study investigated the occurrence of adverse cardiac events in a period of 30 days of postdischarge in those patients with non-cardiac diagnosis of chest pain. Forty-one percent of chest pain patients were admitted to $\mathrm{CCU}$ with diagnosis of ACS. The rate of hospitalization with ACS diagnosis was similar with other studies (1, 3-7).

Fifty-nine percent of patients were discharged with non-cardiac chest pain diagnosis. We found cardiac events in $3.1 \%$ of those non-cardiac chest pain patients which is slightly higher than other studies from developed countries. The likely reasons for this difference are adherence to guidelines by physicians, using computer-assisted tools and 
quality assurance of patients' assessment in different times of day $(1,6)$.

Many guidelines have been developed to better clarify the best approach to the diagnosis of cardiac chest pain at EDs. Most of the guidelines provide physicians with reasonably reliable strategies to diagnose cardiac chest pain accurately. However, no guideline can guarantee $100 \%$ accurate diagnosis $(4,6)$.

Loten et al. reported rate of adverse cardiac events postdischarge as $1 \%$ over one month (1) and Christenson et al. reported a rate of $1.8 \%$ over one month (7). However, Miller et al. reported it to be $2.8 \%$ over one month (2), and Montassier et al. reported it as $3.7 \%$ over two months (3). The gap between the results of these studies and ours suggests the need for more adherence to guidelines in ED and for better supervision of registrars in our setting.

In this study, the cardiac events were significantly higher in older patients, those discharged against medical advice, those with hypertension, dyslipidemia and previous CAD similar to what was reported by Miller et al. (2). Also, in Prina LD's study, the patients with abnormal ECG, previous CAD and diabetes were at higher risk for postdischarge cardiac events (8). It was shown that abnormal ECG, previous MI and hypertension were predictors of adverse outcome post discharge (9). Therefore, in patients with history of previous CAD, abnormal baseline ECG, hypertension, older age and other risk factors, more attention is needed during evaluation in ED.

DAMA is several folds higher in Iran compared to developed countries. Shirani et al. reported 20.2\% DAMA in a general referral hospital in Tehran (10). Nonetheless, DAMA was reported between $0.8 \%$ to $2.2 \%$ of all discharges in the US $(11,12)$. In Kashan, a city in central Iran with similar population to Yazd, DAMA was $11.6 \%$ of all discharges (13). DAMA in pediatric hospitals $(5.3 \%)$ is also higher in Iran compared to other countries (14). There are several reasons reported for discharge against medical advice in developed countries including feeling better and having personal and financial obligations $(11,15)$. In Iran, reasons for DAMA are reported as personal obligations, quality of hospital staff and hospital environment $(13,16)$.
According to the literature, physicians should pursue a more extensive workup than a history, physical examination and ECG in patients with typical angina, known coronary artery disease, and coronary risk factors (4). Limitations in diagnosis equipment such as cardiac radio isotope scan and CT angiography may result in under-diagnosis of the condition.

Several limitations of this study should be mentioned. First of all, it is not clear how the ED registrar in this study made the determination that a patient had "non-angina" chest pain. Second, formal criteria were not established, and the investigators did not report detailed history and physical examinations of patients. Furthermore, data on the history of CVD, tobacco smoking, dyslipidemia and hypertension were based on self-report which was otherwise difficult to assess in emergency situation. This is the first study of its kind in developing countries which shows some different determinants compared to developed countries.

In conclusion, adverse cardiac event and DAMA are higher in our patients compared to developed countries. DAMA is a main factor influencing adverse cardiac events of postdischarge from ED. Further studies are needed to investigate the reasons for DAMA.

Having evidence-based guidelines and relevant algorithms, quality assurance of services over different time of the day, and also having a nation-wide registry may help for better follow up of those patients discharged with noncardiac chest pain as diagnosis.

\section{REFERENCES}

1. Loten C, Isbister G, Jamcotchian M, Hullick C, MacElduff P, Attia J, Marley J. Adverse outcomes following emergency department discharge of patients with possible acute coronary syndrome. Emergency Medicine Australasia 2009; 21: 455-64.

2. Miller CD, Lindsell CJ, Khandelwal S, Chandra A, Pollack CV, Tiffany BR, et al. Is the initial diagnostic impression of "noncardiac chest pain" adequate to exclude cardiac disease? Annals of emergency medicine 2004; 44: 565-74.

3. Montassier E, Batard E, Gueffet JP, Trewick D, Le Conte P. Outcome ofChest Pain 
Patients Discharged From a French Emergency Department: A 60-day Prospective Study. The Journal of Emergency Medicine 2012; 42: 341-44.

4. Anderson JL, Adams CD, Antman EM, Bridges CR, Califf RM, Casey DE, et al. ACC/AHA 2007 Guidelines for the Management of Patients With Unstable Angina/Non-ST-Elevation Myocardial InfarctionA Report of the American College of Cardiology/American Heart Association Task Force on Practice Guidelines (Writing Committee to Revise the 2002 Guidelines for the Management of Patients With Unstable Angina/Non-ST-Elevation Myocardial Infarction) Developed in Collaboration with the American College of Emergency Physicians, the Society for Cardiovascular Angiography and Interventions, and the Society of Thoracic Surgeons Endorsed by the American Association of Cardiovascular and Pulmonary Rehabilitation and the Society for Academic Emergency Medicine. Journal of the American College of Cardiology 2007; 50: e1-e157.

5. BonowRO, Ganiats TG, Beam CT, Blake K, Casey DE, Goodlin SJ, et al. ACCF/AHA/AMA-PCPI 2011 Performance Measures for Adults With Heart FailureA Report of the American College of Cardiology Foundation/American Heart AssociationTask Force on Performance Measures and the American Medical Association-Physician Consortium for Performance Improvement. Journal of the American College of Cardiology 2012; 59: 1812-32.

6. Lindsell CJ, Anantharaman V, Diercks D, Han JH, Hoekstra JW, Hollander JE, et al. The Internet Tracking Registry of Acute Coronary Syndromes (i* trACS): A Multicenter Registry of Patients With Suspicion of Acute Coronary Syndromes Reported Using the Standardized Reporting Guidelines for Emergency Department Chest Pain Studies. Annals of emergency medicine 2006; 48: 666-77. e9.

7. Christenson J, Innes $\mathrm{G}$, McKnight $\mathrm{D}$, Boychuk B, Grafstein E, Thompson CR, et al. Safety and efficiency of emergency department assessment of chest discomfort. Canadian Medical Association Journal 2004; 170: 1803-078.

8. PrinaLD, Decker WW, Weaver AL, High WA, Smars PA, Locke GR 3rd, et al. Outcome of patients with a final diagnosis of chest pain of undetermined origin admitted under the suspicion of acute coronary syndrome: a report from the Rochester Epidemiology Project. Ann Emerg Med 2004 Jan; 43(1):59-67.

9. Glover CL, Benink E, Tudor G, Aldag J, Smith M. Outcome analysis of chest pain patients discharged from the ED--a pilot study. Am $J \quad$ Emerg Med 2000;18(7):779-8.

10. Shirani F, Jalili M, Asl-e-Soleimani H. Discharge against medical advice from emergency department: results from a tertiary care hospital in Tehran, Iran. European Journal of emergency medicine 2010; 17: 318-21.

11. Weingart SN, Phillips RS. Patients discharged against medical advice from a general medicine service. Journal of general internal medicine 1998; 13: 568-71.

12. Saitz R, Ghali WA, Moskowitz MA. The impact of leaving against medical advice on hospital resource utilization. Journal of general internal medicine 2000; 15: 103-07.

13. Rangraz Jeddi F, Rangraz jeddi $M$, Rezaeiimofrad M. Patients' reasons fordischarge against medical advice in university hospitals of Kashan University of Medical Sciences in 2008. Hakim Research Journal 2010; 13: 33-39.

14. Kabirzadeh A, Rezazadeh A, Mohseni Saravi B. Reason for discharge with personal consent of pediatrics' patients of Boali Hospital of Sary in 2008. Journal of North Khorasan University of Medical Sciences 2011; 2: 57-62.

15. Jeremiah J, O’Sullivan P, Stein MD. Who leaves against medical advice? Journal of general internal medicine 1995; 10: 403-05.

16. Manouchehri J, Goodarzyneja H, Khoshgoftar Z, Fathollahi MS, Abyaneh MA. Discharge against Medical Advice among Inpatients with Heart Disease in Iran. The Journal of Tehran University Heart Center 2012; 7:72-77. 